\title{
Estimated dietary exposure to veterinary residues in chicken and eggs
}

\author{
Godfred Darko ${ }^{*}$, John Kenneth Mensah, Sylvester Samuel Dapaah and Judith Odei
}

\begin{abstract}
Background: Chicken tissues and eggs were analyzed for residues of eight veterinary drugs including albendazole, piperazine, tiamulin, chloramphenicol, levamisole, sulphathiazole, sulphamethoxazole and oxytetracyclineoxytetracycline.

Results: Mean residue concentrations of all drugs varied by tissue and ranged from $0.004 \mu \mathrm{g} / \mathrm{kg}$ for tiamulin in eggs to $8.6 \mu \mathrm{g} / \mathrm{kg}$ for chloramphenicol in liver. Total residues of all drugs in the liver generally exceeded that of the kidney, muscles and eggs by at least a two-fold difference. The general order of decreasing total drug residue levels is liver > kidney > muscle > eggs. The exposure due to albendazole and sulphamethoxazole in liver were 2- and 7-folds higher than their recommended average daily intake. Exposure due to piperazine, sulphamethoxazole, levamisole and tiamulin were, however, lower than their respective recommended limits.

Conclusion: Dietary exposure assessments of all drugs based on quantitated residue levels are within the Joint FAO/ WHO Expert Committee on Food Additives safe regulatory exposure limits. This study informs the public about veterinary drug residues in poultry and helps address policy and regulatory changes in the use of veterinary drugs in poultry.
\end{abstract}

Keywords: Poultry, Veterinary, Drugs, Residues

\section{Background}

Veterinary drugs are routinely used on poultry for therapy and for prophylaxis that may encompass control and prevention of diseases (Reig and Toldra 2008), assistance in relieving stress (Kao et al. 2001), rehydration of livestock (Kao et al. 2001; Stolker et al. 2007), promotion of growth (Kabir et al. 2004) and stimulation of egg production (Kabir et al. 2004). The use of veterinary drugs is prevalent in modern animal husbandry. It is estimated that $80 \%$ of all food-producing animals receive, at least, a regimen of drug medication during their life time (Pavlov et al. 2008).

Consequently, incorrect use of veterinary drugs such as overdose, inappropriate use times, failure to observe the label instruction and non-observance of withdrawal periods prior to slaughter or to laying of eggs may leave residues of drugs in tissues and eggs at concentrations that may be harmful to human health (Kabir et al. 2004; Goetting et al. 2011; Kehinde et al. 2012; Omeiza et al. 2012). Chronic and acute human exposure to veterinary drugs through ingestion of their residues in poultry

\footnotetext{
* Correspondence: godfreddarko@yahoo.com

Department of Chemistry, Kwame Nkrumah University of Science and Technology, Kumasi, Ghana
}

products are associated with the development of allergic reaction in hypersensitive individuals (Shankar et al. 2010), the alteration of human intestinal micro-flora (Shankar et al. 2010) as well as induction and generation of resistant strains of human pathogenic bacteria (Kabir et al. 2004). The presence of veterinary drug residues in poultry above tolerance levels constitutes a healthcare problem and presents public health concerns (Verbeke and Viaene 2000; Leibler et al. 2004). Safe and appropriate use of veterinary drugs therefore remains one of the most challenging public health issues.

Quantitative assessment of drug residues levels in marketed poultry products is the first step in evaluating the safety of veterinary drugs used in the poultry industry. Whereas the levels of veterinary drugs in poultry is routinely monitored in the developed parts of the world, the developing nations, such as Ghana, still lack a comprehensive study that could potentially spur the enforcement of best practices in poultry farming. Enforcement of best practices is usually lax and farmers do not keep proper records of the drugs administered to the birds in the country. As a first step towards the assessment of potential health risk posed by veterinary drug residues in Ghanaian
照 Springer

(c) 2015 Darko et al. Open Access This article is distributed under the terms of the Creative Commons Attribution 4.0 International License (http://creativecommons.org/licenses/by/4.0/), which permits unrestricted use, distribution, and reproduction in any medium, provided you give appropriate credit to the original author(s) and the source, provide a link to the Creative Commons license, and indicate if changes were made. 
poultry, this study determined the residue levels of 8 commonly used veterinary drugs (chloramphenicol, sulphathiazole, sulphamethoxazole, oxytetracycline, tiamulin, levamisole, piperazine and albendazole) in the tissues of market-ready chicken (liver, kidney and muscles) and in chicken eggs originating from farms in the Offinso, Kumasi and the Kwabre Districts of the Ashanti Region of Ghana. The three districts were chosen because of their high localization of poultry farms and their dense urban population that relies heavily on chicken products for their protein needs.

\section{Methods}

\section{Sample collection}

Two hundred chicken eggs and 540 chicken tissues (comprising 180 pieces each of liver, kidney and muscle) were taken from slaughtered, matured and market-ready birds that were randomly selected from farms in three different districts (Offinso, Kwabre and Kumasi) in the Ashanti region of Ghana in 2013. The samples cover all the available chicken poultry products that would have been offered for sale at the retail market. All samples were stored on ice and transported to the laboratory. Eggs were kept in the refrigerator while chicken tissues were frozen at $-20{ }^{\circ} \mathrm{C}$ until analysis. Since the emphasis of sampling was on obtaining samples that reflect the broad range of chicken poultry products consumed in the Ghanaian home, the exact age of birds, the dose of veterinary drugs used and the frequency of drug use were not controlled in this study. All birds were matured and market-ready and all eggs were freshly laid. All muscles were comprised of breast tissue.

\section{Reagents}

Acetonitrile $(\mathrm{MeCN})$, methanol $(\mathrm{MeOH})$ and hexane were of HPLC grade (Fisher Scientific, UK). Potassium dihydrogen phosphate and sodium dihydrogen phosphate were of reagent grade (Fisher Scientific, UK). Standards of veterinary drugs provided in ampules include sulphathiazole, sulphamethoxazole, tiamulin, oxytetracycline, albendazole, piperazine, chloramphenicol and levamisole (Sigma-Aldrich, St. Louis, USA).

\section{Standard solutions}

Stock solutions $(100 \mathrm{mg} / \mathrm{mL})$ of each of the eight drug standards were prepared by pipetting the appropriate aliquot into a $25 \mathrm{~mL}$ volumetric flask and then dissolving and diluting to the mark with $\mathrm{MeCN}: \mathrm{MeOH}$ (30:70) solution. Stock solutions were stored refrigerated and prepared fresh every 3 months. Working solutions of standards $(100 \mu \mathrm{g} / \mathrm{mL}$ and $10 \mu \mathrm{g} / \mathrm{mL})$ were freshly prepared through dilution of an appropriate aliquot of the stock solutions with $\mathrm{MeCN}: \mathrm{MeOH}$ (30:70) solution. They were stored refrigerated and prepared fresh monthly. The blank standard was taken to be the dilution solution of $\mathrm{MeCN}$ :$\mathrm{MeOH}$ (30:70) with no added drug. Distilled water was used to prepare all aqueous solutions. All solutions prepared for HPLC were filtered through a $0.45 \mu \mathrm{m}$ nylon filter before use.

\section{Sample extraction Chicken tissue}

Tissues samples were minced and ground to homogeneity using a food processor. Homogenized tissues were then kept frozen at $-20{ }^{\circ} \mathrm{C}$ until use. To $5.0 \mathrm{~g}$ of the homogenized tissue was added $50 \mathrm{~mL} \mathrm{MeCN}$ and the mixture shaken vigorously for $3 \mathrm{~min}$ in a $100 \mathrm{~mL}$ centrifuge tube. The tube was centrifuged and the supernatant filtered into fresh containers. The residue was extracted two additional times, each time with $50 \mathrm{~mL}$ of $\mathrm{MeCN}$ and the filtrate pooled. The combined filtrate was transferred into a separatory funnel containing $30 \mathrm{~mL}$ of $\mathrm{MeCN}$ saturated $\mathrm{n}$-hexane and shaken for $5 \mathrm{~min}$. The $\mathrm{MeCN}$ layer was collected into a flask and the $\mathrm{MeCN}$ evaporated to dryness under vacuum on a rotavap (Buchi, USA).

\section{Eggs}

Whole eggs were homogenized in an Ultra-Turrax T25 basic homogenizer (Staufen, Germany) for $1 \mathrm{~min}$ at $7000 \mathrm{rpm}$. A $2 \mathrm{~mL}$ aliquot of homogenized egg sample and $20 \mathrm{~mL}$ of $\mathrm{MeCN}$ were blended together at high speed in the homogenizer for $5 \mathrm{~min}$ and the supernatant filtered through a Whatman $0.45 \mu \mathrm{m}$ filter paper. Two additional homogenization with $\mathrm{MeCN}$ and filtration were performed. The combined filtrate was transferred into a separatory funnel containing $30 \mathrm{~mL}$ portion of $\mathrm{MeCN}$-saturated $\mathrm{n}$-hexane and the mixture shaken for $5 \mathrm{~min}$. The MeCN layer was collected into a concentration bottle and reduced to dryness under vacuum on a rotavap (Buchi, USA).

\section{Sample clean-up}

Extracts were cleaned up using $\mathrm{C}_{18}$ sorbent columns (Supelclean, $1 \mathrm{~g} \times 6 \mathrm{~mL}$, ENVI-18 SPE cartridge) from Sigma-Aldrich, USA. The absorbent was pre-conditioned by sequential washing with $10 \mathrm{~mL}$ of methanol and $10 \mathrm{~mL}$ of $0.05 \mathrm{M}$ sodium dihydrogen phosphate solution. The semi-dry residues emanating from tissue and egg extraction were re-dissolved in $10 \mathrm{~mL}$ of sodium dihydrogen phosphate solution and applied onto the ENVI-18 SPE cartridge. The concentration bottle was washed with $5 \mathrm{~mL}$ sodium dihydrogen phosphate solution and $5 \mathrm{~mL} \mathrm{MeOH}$ and applied to the SPE column. The eluate was collected into a $15 \mathrm{~mL}$ polypropylene centrifuge tubes and evaporated to dryness at $40{ }^{\circ} \mathrm{C}$ in a rotary evaporator. The dry matter was reconstituted with $1 \mathrm{~mL}$ of $\mathrm{MeCN} / \mathrm{H}_{2} \mathrm{O}$ $(3 / 7, \mathrm{v} / \mathrm{v})$ and spiked $0.5 \mathrm{~mL}$ of $\mathrm{MeCN}$ saturated $\mathrm{n}$-hexane. The resulting solution was then centrifuged at $3000 \mathrm{rpm}$ 
for $5 \mathrm{~min}$. The acetonitrile layer was collected and filtered through a $0.45 \mu \mathrm{m}$ nylon membrane prior to HPLC analysis (Kao et al. 2001).

\section{Instrument}

HPLC analysis was carried out on an Agilent 1260 automated HPLC series with an SPD-M6A photodiode array detector operating at $270 \mathrm{~nm}$ wavelength with a $50 \mathrm{~nm}$ bandwidth. A $20 \mu \mathrm{L}$ aliquot of each extracted sample were injected into the RP-18 Mightysil HPLC column $(150 \mathrm{~mL}$, $4.6 \mathrm{~mm}, 15 \mu \mathrm{m}$ ) maintained at $40{ }^{\circ} \mathrm{C}$ with a column heater. All HPLC analysis (tissues and eggs) utilized the same mobile phase that was a 70:30 (v/v) solution of $0.01 \mathrm{M}$ potassium dihydrogen phosphate $\left(\mathrm{KH}_{2} \mathrm{PO}_{4}\right): \mathrm{MeCN}$. Peaks were well resolved within $30 \mathrm{~min}$ run (Fig. 1).

\section{HPLC analysis}

Five calibration standards were prepared from their working stock solutions by transferring the appropriate aliquot and bringing the total volume to $1 \mathrm{~mL}$ using $\mathrm{MeCN} / \mathrm{KH}_{2} \mathrm{PO}_{4}$ buffer. A new set of calibration standards was run before each set of samples were assayed. Calibration standard solutions, reagent blanks and reagent blank spikes for each veterinary drug were HPLC-analyzed in the same way as the sample. Samples were run in eight analytical batches, with each analytical batch consisting of five standards, three reagent blanks and two reagent blank spikes and triplicates of ten samples. In all cases, the concentrations of drug residues in samples were determined by interpolation from a five-point calibration curve generated via measurement of the HPLC peak area.

\section{Limit of detection (LOD)}

The LOD for the solution was initially estimated for each analytical batch as three times the standard deviation of the three reagent blanks. The solution LODs $(\mathrm{mg} / \mathrm{mL})$ are as follows: albendazole (0.001), chloramphenicol (0.001), levamisole (0.001), oxytetracycline (0.002), piperazine (0.001) and sulphamethoxazole (0.001), sulphathiazole (0.001) and tiamulin (0.001). Sample LODs were then calculated for each drug by multiplying the solution limit of detection by the dilution volume and dividing by the weight of the actual sample. The sample LOD $(\mathrm{mg} / \mathrm{kg})$ are as follows: albendazole (0.025), chloramphenicol (0.025), levamisole (0.025), oxytetracycline $(0.025)$, piperazine (0.015) and sulphamethoxazole (0.025), sulphathiazole (0.025) and tiamulin (0.002).

\section{Quality assurance and quality control measures}

To ensure the validity of results, the following measures were taken. Prior to sample analysis, standards for all 8 drugs were analyzed to verify adequate system performance. Agreement of HPLC data with analyzed standards prior to sample analyses and in between ten sample runs were satisfactory. Each batch of sample analysis was prepared to include reagent blank in triplicate to control for background contamination and three spiked samples in triplicate to confirm satisfactory drug recovery greater than $70 \%$. In addition, the correlation coefficient for the

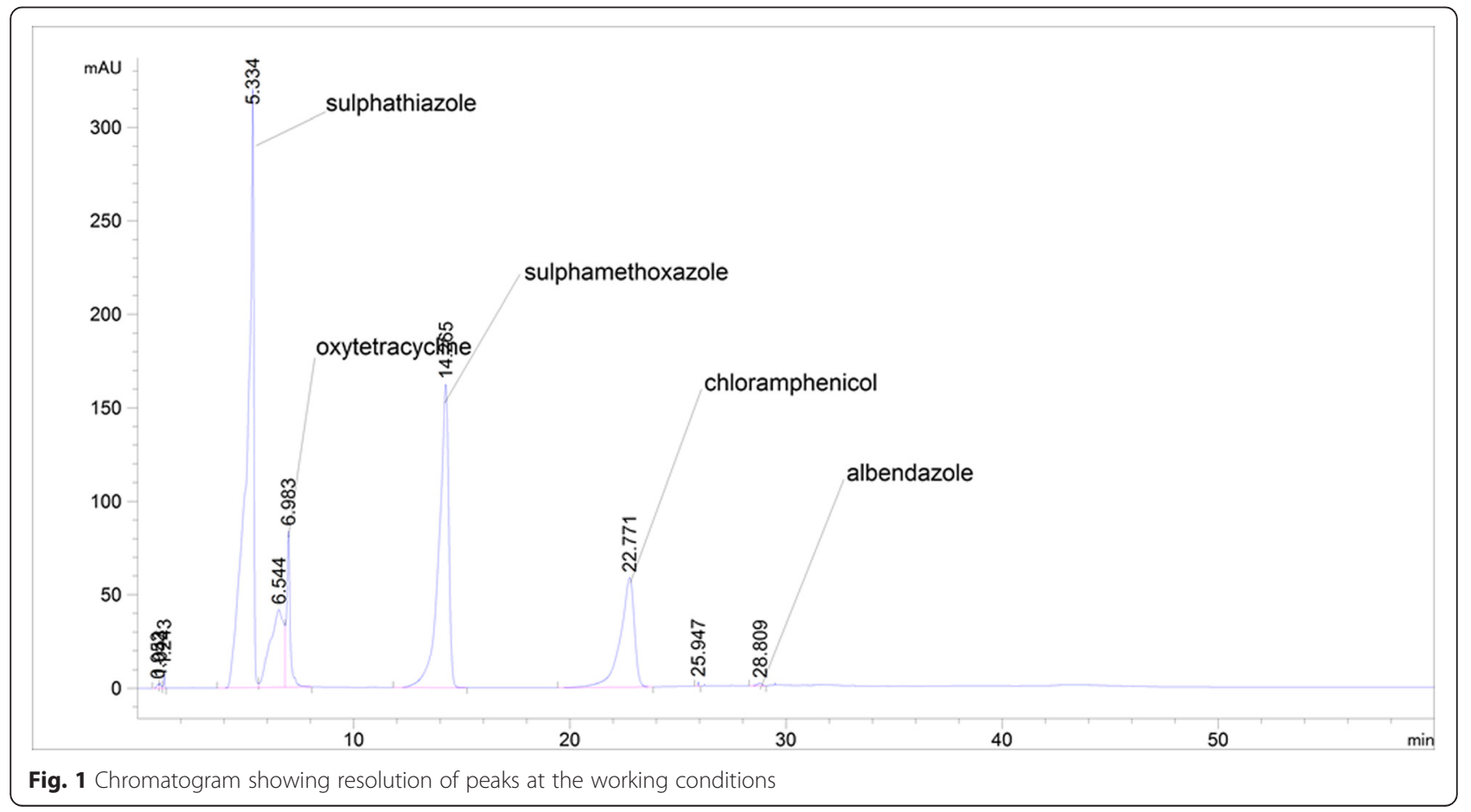


calibration curve was required to be greater than 0.995 . All samples were analyzed in triplicates.

\section{Recovery of spiked samples}

Recovery test was performed in triplicate by spiking standards at three different levels of the veterinary drugs. Five gram of homogenized samples were spiked with $5 \mu \mathrm{L}$ of internal working standard solution $(10 \mu \mathrm{g} / \mathrm{mL})$ and vortexed for $1 \mathrm{~min}$ to mix thoroughly. Spiked and unknown samples are treated in the same way. Average recoveries registered were in the range of $76.0-98.8 \%$. For both tissues and eggs, sulphamethoxazole and tiamulin showed the least recovery with mean values between $76.0-78.0 \%$ respectively, while albendazole obtained the highest mean recoveries at $98.0-98.8 \%$.

\section{Statistical analysis}

All data were reported as the mean \pm standard deviation of the set of triplicates determinations. A one way analysis of variance (ANOVA) was conducted using GraphPad prism 5 in the assessment of variation in drug concentrations within same tissues and between different tissues. Tests were considered statistically significant at $p<0.05$.

\section{Dietary exposure assessment}

Dietary exposure was quantitatively estimated using as input, the food consumption data and the total concentrations of residues found in chicken tissues and in eggs (FAO/WHO 2011). Dietary exposure (acute and chronic) was computed using expression (1) assuming an average adult weight of $60 \mathrm{~kg}$ (FAO/WHO 2004; FAO/WHO 2005).

\section{Dietaryexpoure$$
=\frac{\sum \text { Residue concentration } x \text { Acceptable dailyintake }}{\text { Bodyweight }}
$$

Global estimated acute dietary exposure (GEADE) was calculated based on the 97.5th percentile food consumption amount using equation (2) as:

$$
\begin{aligned}
& \text { GEADE } \\
& =\frac{97.5^{\text {th }} \text { percentile food consumption } x \text { high residue tissue }}{\text { Bodyweight }}
\end{aligned}
$$

The 97.5th percentile food consumption amount was used because of its statistical robustness and is more representative than the maximum food consumption amount (FAO/WHO 2005; FAO/WHO 2011). Global estimated chronic dietary exposure was calculated as the product of the highest exposure animal product and total mean exposure (JECFA 2014).

\section{Results and discussion}

Sampled farms cover three urban district areas located in the Ashanti region of Ghana (Fig. 2). The farms follow different drug use protocols that include more than one use frequency at different doses and at different times for either therapy or prophylaxis or for both. None of the sampled farms observed withdrawal period of the drugs prior to slaughter or harvesting of eggs.

Albendazole occurred in $77.8 \%$ of the chicken breast samples at an average concentration of $230.6 \pm$ $29.2 \mu \mathrm{g} / \mathrm{kg}$ which was about two times higher than the recommended MRL of $100 \mu \mathrm{g} / \mathrm{kg}$ (EMEA 2004). In eggs, the incidence was $66 \%$ at a concentration of $64.8 \pm 4.2 \mu \mathrm{g} / \mathrm{kg}$. Piperazine had an average concentration of $33.8 \pm 6.8 \mu \mathrm{g} / \mathrm{kg}$ in $25 \%$ of the samples. In chicken, it was detected in $50 \%$ of the chicken samples analyzed at mean concentration of $63.3 \pm 1.8 \mu \mathrm{g} / \mathrm{kg}$ which was less than recommended limit of $100 \mu \mathrm{g} / \mathrm{kg}$ (JECFA 2014). The usual metabolites of albendazole namely albendazole sulfoxide, albendazole sulfon and albendazole-2-aminnosulfon (McKellar et al. 1993) were not measured in this work.

Sulphathiazole was not detected in the egg samples but it occurred in chicken at an average concentration of $199.2 \pm 3.9 \mu \mathrm{g} / \mathrm{kg}$ which was about five times lower than the JEFCA recommended MRLs of $1000 \mu \mathrm{g} / \mathrm{kg}$ (JECFA 2014). Sulphamethoxazole was detected in $56 \%$ of the chicken samples at an average concentration of $65.7 \pm$ $2.1 \mu \mathrm{g} / \mathrm{kg}$ which was about eight times lower than the recommended limits of $1000 \mu \mathrm{g} / \mathrm{kg}$ (JECFA 2014). Sulphamethoxazole was however not detected in the egg samples. Concentration of 13 sulphonamides (including sulphathiazole and sulphamethoxazole) detected in chicken samples from 11 states in Malaysia ranged from 6-62 $\mu \mathrm{g} / \mathrm{kg}$ in chicken breast muscle samples (Cheong et al., 2010). Sulphamethoxazole was detected in $10 \%$ of the egg samples at an average concentration of $15.5 \pm$ $0.1 \mu \mathrm{g} / \mathrm{kg}$.

Oxytetracycline occurred at an average concentration of $83.7 \pm 1.6 \mu \mathrm{g} / \mathrm{kg}$ in $61 \%$ of the chicken samples. These concentrations are about seven times lower than the FAO/WHO recommended MRLs of $600 \mu \mathrm{g} / \mathrm{kg}$. In eggs, the average concentration of oxytetracycline was found to be $21.8 \pm 0.1 \mu \mathrm{g} / \mathrm{kg}$ for $61 \%$ samples that tested positive.

Chloramphenicol was the most commonly found residue in the chicken as it was determined in about $88.9 \%$ of the samples at an average concentration of $150.1 \pm 19.5 \mu \mathrm{g} / \mathrm{kg}$. This gives some indications that the drug is frequently used. However, the residual concentration of the chloramphenicol was about 3 times lower than the recommended limit of $500 \mu \mathrm{g} / \mathrm{kg}$ (EMEA 2001). In a study conducted in Iran, more than half of the chicken samples (54.8\%) showed detectable 


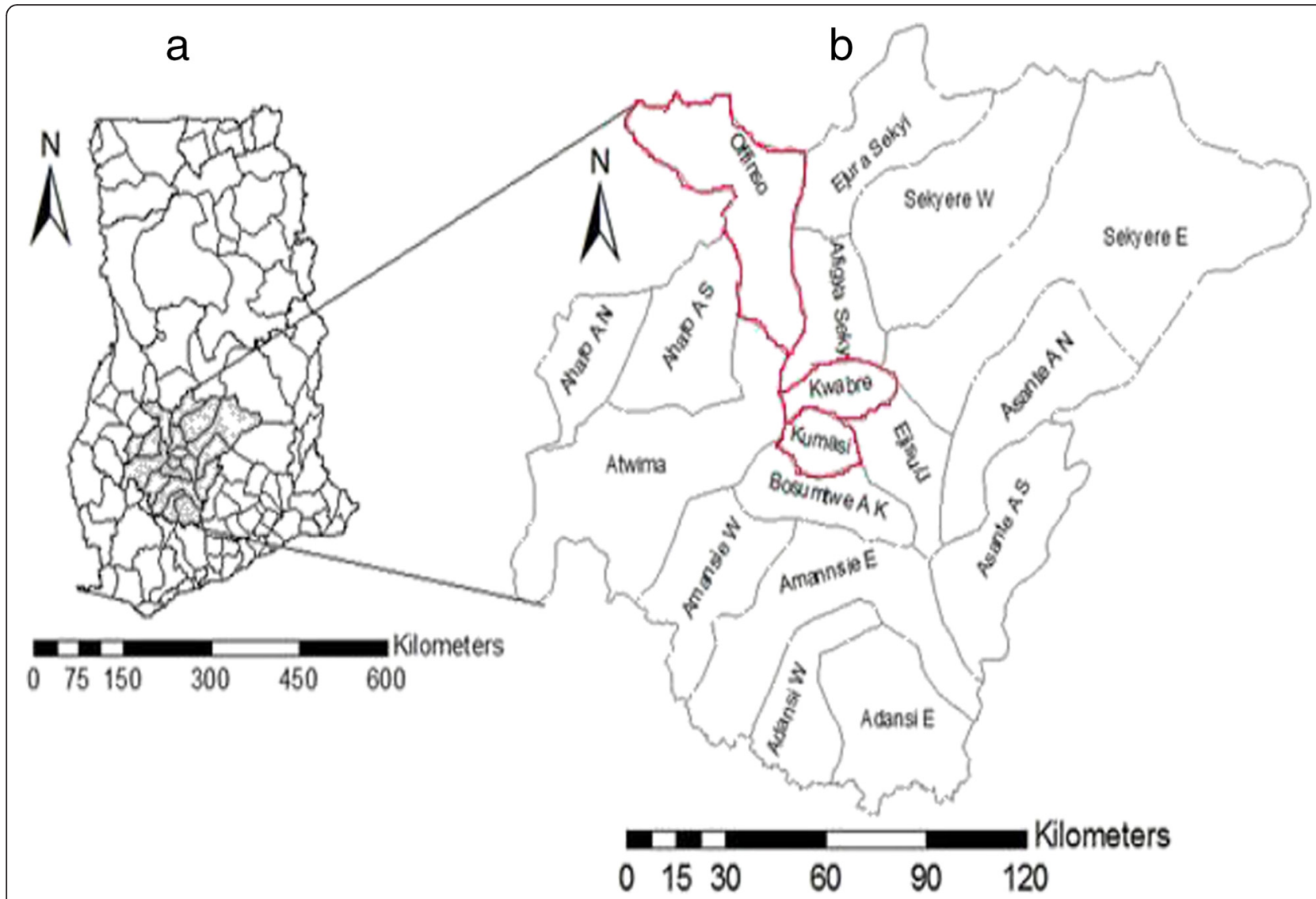

Fig. 2 Map of the study area depicting: a the location of Ashanti region (shaded gray) in Ghana and $\mathbf{b}$ the three sampled Districts: Offinso, Kwabre and Kumasi (outlined in red)

concentrations of chloramphenicol (Mehdizadeh et al. 2010). In Nigeria, $33.3 \%$ of 105 poultry farmers interviewed were not aware of the legislation governing the use of chloramphenicol in food for animals (Kehinde et al. 2012). Twenty-five percent of the egg samples tested positive for chloramphenicol which registered an average concentration of $29.6 \pm 0.6 \mu \mathrm{g} / \mathrm{kg}$.

Tiamulin showed the least detectable residue in the chicken, occurring at a mean concentration of $31.1 \pm$ $9.8 \mu \mathrm{g} / \mathrm{kg}$ in $11.1 \%$ samples which is about 30 times less than the FAO/WHO recommended MRLs of $1000 \mu \mathrm{g} / \mathrm{kg}$. The concentration in eggs was only $4.8 \pm 0.1 \mu \mathrm{g} / \mathrm{kg}$ at $25 \%$ incidence. This concentration is not expected to pose health risks to consumers since they are far below the FAO/WHO recommended MRLs. It should however be noted that metabolites of tiamulin; $2-\beta$-hydroxy-N-dimethyl-tiamulin and 8- $\alpha$-hydroxy-N-dimethyl-tiamulin (Lykkeberg et al. 2006) were not measured in this work.

Six of the eight drugs including albendazole, piperazine, chloramphenicol, levamisole, sulphathiazole and sulphamethoxazole recorded their highest total concentrations in the liver. Except tiamulin that showed very low liver residual levels, liver residues of all drugs were higher than muscles residues by at least two-fold difference and higher than egg residues by at least five-fold difference. Relatively high concentrations of the residues in the liver implicates it as first site of biochemical action for the drugs' metabolism. Oxytetracycline and tiamulin deviate from the pattern of quantitative distribution exhibited by the 6 other drugs. Highest residues of oxytetracycline were recorded in the kidney with a marginally lower value in the liver. Similarly, the highest recorded value of tiamulin were found in the kidney while the liver showed a 4-fold decrease in residual levels. The highest recorded concentrations of tiamulin and oxytetracycline in the kidney suggest that the kidney is possibly the first site for the metabolism of both drugs.

As an antibiotic, the highest recorded concentration of chloramphenicol in liver and in muscle suggest either higher administered doses or higher frequency of use. Concentration of albendazole in the kidney was marginally lower than that in the liver but ebbs to an almost 4-fold decrease in muscles and to an 8-fold decrease in eggs relative to the concentrations found in the liver. A similar pattern of distribution was shown by piperazine and levamisole. Sulphathiazole was singularly unique in having concentrations in muscles greater than those in 
kidney by about 1.2 fold. For all veterinary drugs, residues in eggs were the lowest in quantitative amounts compared to residues in tissues and this observation suggests a likely dose-dependent drug transported from the liver or from the kidney to the developing egg during oviposition. Albendazole exhibited the highest residual levels in eggs while tiamulin recording the lowest level.

\section{Dietary exposure assessment}

Table 1 shows the dietary exposure estimates for veterinary drug residues. Chloramphenicol recorded the highest concentration of $8.598 \mu \mathrm{g} / \mathrm{kg}$ in liver samples, followed by sulphathiazole $(4.946 \mu \mathrm{g} / \mathrm{kg})$ and albendazole $(4.267 \mu \mathrm{g} / \mathrm{kg}$. In the muscle samples, chloramphenicol recorded $1.396 \mu \mathrm{g} / \mathrm{kg}$, followed by sulphathiazole $(1.297 \mu \mathrm{g} / \mathrm{kg})$ and albendazole $(1.013 \mu \mathrm{g} / \mathrm{kg})$. Albendazole registered the highest concentration $(3.878 \mu \mathrm{g} / \mathrm{kg})$ in kidney samples, closely followed by chloramphenicol which also recorded $3.039 \mu \mathrm{g} / \mathrm{kg}$. Oxytetracycline recorded $3.60 \mu \mathrm{g} / \mathrm{kg}$ in kidney samples. Tiamulin recorded the lowest concentration of drug residues in each case in all the three parts. Acute dietary exposure estimates cover a time period of food consumption over a single meal or $24 \mathrm{~h}$ and are intended to be used for comparison with acute reference dose $\left(A R_{f} D\right)$ values in a risk assessment process. The $A R_{f} D$ of veterinary drugs studied have not yet been established.

\section{Global estimated acute dietary exposure assessments}

The global estimated acute dietary exposure for the veterinary drugs residues studied have not yet been established. Computed Global estimated acute dietary exposure assessments (GEADE) of each drug residue was therefore compared to its average daily intake (ADI). Sulphamethoxazole recorded the highest GEADE for the drug residues understudy. It recorded $0.028 \mu \mathrm{g} / \mathrm{kg}$ compared to tiamulin and levamisole which recorded the lowest global estimated acute dietary exposure of 0.00016 and $0.0002 \mu \mathrm{g} / \mathrm{kg}$ respectively. The global estimated acute dietary exposure of albendazole in liver, kidney and muscles samples were $0.012,0.011$ and $0.010 \mu \mathrm{g} / \mathrm{kg}$ respectively (Table 2). Chloramphenicol recorded the highest GEADE of $0.031,0.024$ and $0.012 \mu \mathrm{g} / \mathrm{kg}$. It was closely followed by levamisole which also recorded 0.013 , 0.024 and $0.020 \mu \mathrm{g} / \mathrm{kg}$. Tiamulin and piperazine recorded the lowest global estimated acute dietary exposure. The GEADE of all the drug residues were lower than their respective ADI. This imply the concentrations of the drug residues found in the samples do not present acute toxicity to consumers.

\section{Chronic dietary exposure assessments}

From Table 2, chloramphenicol residues in liver samples registered the highest level of exposure of $0.461 \mu \mathrm{g} / \mathrm{kg}$, followed by sulphamethazole $(0.148 \mu \mathrm{g} / \mathrm{kg})$. The exposure of albendazole in liver sample was about two times higher than the recommended ADI of $0.05 \mu \mathrm{g} / \mathrm{kg}$ whiles sulphamethazole recorded an exposure seven times higher than the recommended ADI of $0.02 \mu \mathrm{g} / \mathrm{kg}$. Chloramphenicol in liver samples recorded the highest level of exposure. The exposure to piperazine, sulphamethoxazole, levamisole and tiamulin were lower than their respective recommended ADI.

Albendazole recorded highest concentration in kidney samples which was about two times higher than the recommended ADI of $0.05 \mu \mathrm{g} / \mathrm{kg}$. Chloramphenicol recorded $0.079 \mu \mathrm{g} / \mathrm{kg}$ exposure and closely followed by oxytetracycline which registered $0.074 \mu \mathrm{g} / \mathrm{kg}$. Oxytetracycline was also about two times higher than the recommended ADI of $0.03 \mu \mathrm{g} / \mathrm{kg}$. The others were lower than the recommended ADI's. Oxytetracycline registered the highest level of exposure $(0.054 \mu \mathrm{g} / \mathrm{kg})$ in the muscle samples which was about two times higher than the recommended ADI. Chloramphenicol which has no ADI also recorded $0.017 \mu \mathrm{g} / \mathrm{kg}$ from muscle samples. The rest of the residues were lower than the recommended ADI values.

Table 1 General considerations for dietary exposure estimates for veterinary drug residues $(\mu \mathrm{g} / \mathrm{kg})$

\begin{tabular}{|c|c|c|c|c|c|}
\hline \multirow[t]{2}{*}{ Drug residues } & \multicolumn{2}{|c|}{ Concentration chemical in food ( $\mu \mathrm{g} / \mathrm{kg}$ ) } & \multicolumn{2}{|c|}{ Food consumption ( $\mu \mathrm{g} / \mathrm{kg})$} & \multirow[t]{2}{*}{ GEADE $(\mu \mathrm{g} / \mathrm{kg})$} \\
\hline & Liver & Kidney & Muscle & ADI & \\
\hline Albendazole & 4.267 & 3.878 & 1.013 & 0.05 & 0.007 \\
\hline Piperazine & 1.989 & 1.990 & 0.521 & 0.25 & 0.018 \\
\hline Sulphathiazole & 4.946 & 1.074 & 1.297 & 0.02 & 0.002 \\
\hline Sulphamethoxazole & 1.182 & 0.477 & 0.335 & 0.05 & 0.028 \\
\hline Levamisole & 1.965 & 1.674 & 0.9980 & 0.003 & 0.0002 \\
\hline Oxytetracycline & 3.198 & 3.600 & 1.083 & 0.03 & 0.0039 \\
\hline Chloramphenicol & 8.598 & 3.039 & 1.396 & - & - \\
\hline Tiamulin & 0.052 & 0.242 & 0.038 & 0.03 & 0.00016 \\
\hline
\end{tabular}


Table 2 Chronic dietary exposure estimates for veterinary drug residues $(\mu \mathrm{g} / \mathrm{kg})$

\begin{tabular}{|c|c|c|c|c|c|c|c|c|c|}
\hline \multirow[t]{2}{*}{ Drug residues } & \multicolumn{9}{|c|}{ 97.5th percentile consumption ( $\mu \mathrm{g} / \mathrm{kgbody}$ weight per day or $\mathrm{kg} /$ day) } \\
\hline & Liver & $\begin{array}{l}\text { Median residue } \\
(\mu \mathrm{g} / \mathrm{kg})\end{array}$ & $\begin{array}{l}\text { High-level } \\
\text { exposure }\end{array}$ & Kidney & $\begin{array}{l}\text { Median residue } \\
(\mu \mathrm{g} / \mathrm{kg})\end{array}$ & $\begin{array}{l}\text { High-level } \\
\text { exposure }\end{array}$ & Muscle & $\begin{array}{l}\text { Median residue } \\
(\mu \mathrm{g} / \mathrm{kg})\end{array}$ & $\begin{array}{l}\text { High-level } \\
\text { exposure }\end{array}$ \\
\hline Albendazole & 0.956 & 0.112 & 0.106 & 0.821 & 0.103 & 0.085 & 0.307 & 0.029 & 0.009 \\
\hline Piperazine & 0.727 & 0.007 & 0.005 & 0.690 & 0.000 & 0.000 & 0.172 & 0.008 & 0.001 \\
\hline Sulphathiazole & 1.621 & 0.092 & 0.148 & 0.304 & 0.028 & 0.009 & 0.909 & 0.009 & 0.008 \\
\hline Sulphamethoxazole & 0.894 & 0.000 & 0.000 & 0.403 & 0.000 & 0.000 & 0.124 & 0.000 & 0.000 \\
\hline Levamisole & 0.906 & 0.000 & 0.000 & 0.730 & 0.000 & 0.000 & 0.859 & 0.000 & 0.000 \\
\hline Oxytetracycline & 0.926 & 0.011 & 0.010 & 0.867 & 0.086 & 0.074 & 0.315 & 0.016 & 0.054 \\
\hline Chloramphenicol & 0.931 & 0.496 & 0.461 & 0.718 & 0.111 & 0.079 & 0.385 & 0.044 & 0.017 \\
\hline Tiamulin & 0.039 & 0.000 & 0.000 & 0.229 & 0.000 & 0.000 & 0.025 & 0.000 & 0.000 \\
\hline
\end{tabular}

Chronic dietary exposure estimates cover food consumption over the long term and are usually intended to be compare with a chronictoxicity health-based guidance value such as an ADI, in a risk assessment process (Solecki et al. 2005). Therefore albendazole, chloramphenicol and sulphamethazole which recorded chronic dietary exposure higher than their respective ADI may cause health effects to the consumers in the long term.

\section{Global estimated chronic dietary exposure}

The global estimated chronic dietary exposure (GECDE) to the veterinary drug residue for the population group of interest is the highest 97.5th percentile dietary exposure amount for a single food selected from all the foods plus the mean dietary exposure from all the other relevant foods (FAO/WHO 2001; Li et al. 2014).

Chloramphenicol recorded highest global estimated chronic dietary exposure of $1.018 \mathrm{mg} / \mathrm{kg}$ body weight per day whiles albendazole and sulphathiazole registered $0.306 \mathrm{mg} / \mathrm{kg}$ body weight per day and $0.313 \mathrm{mg} / \mathrm{kg}$ body weight per day respectively (Table 3 ). Piperazine and oxytetracycline also recorded $0.011 \mathrm{mg} / \mathrm{kg}$ body weight per day and $0.212 \mathrm{mg} / \mathrm{kg}$ body weight per day. The computed highest and exposure and total exposure were both lower than the GECDE in all the cases. This implies the concentrations of residues found in the samples are not likely to cause chronic effects to consumers.

\section{Conclusion}

In conclusion, this study shows that there were veterinary drugs residues present in all the five farms visited. The concentrations of levamisole and albendazole residues mostly exceeded the recommended FAO/WHO MRLs, whiles others like tiamulin, piperazine and sulphamethoxazole were far below recommended FAO/ WHO MRL. Chloramphenicol was the most frequently detected veterinary drug residue. Most of the veterinary drug residues were concentrated in the liver, followed by the kidney and finally the muscle sample. Levamisole presents poses a higher risk of exposure to the consumers as their mean concentrations mostly exceeded the MRLs. Chloramphenicol residues present in meat and eggs may be injurious to human health because the concentration exceeded the ADI. This indicates that, consumers of poultry and poultry products are predisposed to health hazards and hinders international meat trade from Ghana. It is recommended that poultry and poultry products used as food should be monitored for the presence of residues and metabolites of veterinary drug administered on the birds.

Table 3 Global estimated chronic dietary exposure for veterinary drug residues $(\mathrm{mg} / \mathrm{kg}$ )

\begin{tabular}{llll}
\hline Drug residues & $\begin{array}{l}\text { Highest exposure (mg/kg body } \\
\text { weight per day or mg/day) }\end{array}$ & $\begin{array}{l}\text { Total mean exposure (mg/kg body } \\
\text { weight per day or mg/day) }\end{array}$ & $\begin{array}{l}\text { GECDE (mg/kg body weight per day } \\
\text { or per day or mg/day) }\end{array}$ \\
\hline Albendazole & 0.106 & 0.20 & 0.306 \\
Piperazine & 0.005 & 0.006 & 0.011 \\
Sulphathiazole & 0.148 & 0.165 & 0.313 \\
Sulphamethoxazole & - & - & - \\
Levamisole & - & - & - \\
Oxytetracycline & 0.074 & 0.138 & 0.212 \\
Chloramphenicol & 0.461 & 0.557 & 1.018 \\
Tiamulin & - & - & - \\
\hline
\end{tabular}




\section{Abbreviations}

ADI: average daily intake; FAO: Food and Agriculture Organization; GEADE: Global Estimated Acute Dietary Exposure; GECDE: Global Estimated Chronic Dietary Exposure; HPLC: High Performance Liquid Chromatograph; JECFA: Joint FAO/WHO Expert Committee on Food Additives; LOD: limits of quantification; MeCN: Acetonitrile; $\mathrm{MeOH}$ : Methanol; MRL: maximun residue limits; SPE: solid phase extraction; UK: United Kingdom; USA: United States of America; WHO: World Health Organization.

\section{Competing interests}

We have read and understood Chemistry Central Journal's policy on declaration of interests and all authors declare that we have no competing financial, professional, or personal interests that might have influenced the performance or presentation of the work described in this manuscript.

\section{Authors' contributions}

GD and JKM conceived the study and helped draft the manuscript. All experiments were designed by GD, JKM, SSD and JO. Samples were collected by GD, SSD and JO. All the experiments were carried out by SSD and $\mathrm{JO}$ under the guidance of GD and JKM. All authors read and approved the final manuscript

\section{Authors' information}

Godfred Darko (PhD) is a senior lecturer in Analytical Chemistry. John Kenneth Mensah (PhD) is a lecturer in Organic Chemistry. Samuel Sylvester Dapaah and Judith Odei are Master of Philosophy candidates at the Department of Chemistry, Kwame Nkrumah University of Science and Technology. Kumasi, Ghana.

Received: 22 August 2015 Accepted: 14 December 2015

Published online: 22 December 2015

\section{References}

Cheong CK, Hajeb P, Jinap S, Ismail-Fitry MR. Sulfonamides determination in chicken meat products from Malaysia. Int Food Res J. 2010;892:885-91.

EMEA. The European Agency for the Evaluation of Medicinal Products. Veterinary Medicines Evaluation Unit. Committee for veterinary medicinal products - Chloramphenicol. SUMMARY REPORT 3. EMEA/MRL/505/98 FINAL. London 2001.

EMEA. European Medicines Agency. Committee of medicinal products for veterinary use - Albendazole (Extrapolation to all ruminants) summary report 3. EMEA/MRL/865/03-FINAL. London 2004.

$\mathrm{FAO} / \mathrm{WHO}$. Evaluation of certain veterinary drug residues in food. Sixty-second report of the Joint FAO/WHO Expert Committee on Food Additives. WHO techincal series; 925. Rome, Italy. 2004.

FAO/WHO. Dietary exposure assessment of chemicals in food. Report of a Joint FAO/WHO Consultations and workshops. Annapolis, Maryland, USA 2005.

$\mathrm{FAO}$ WHO. Evaluation of certain veterinary drug residues in food. Fifty-fourth report of the Joint FAO/WHO expert committee report food additives. WHO technical report series. WHO TRS 900. Geneva 2001.

FAO/WHO. Joint FAO/WHO expert meeting on dietary exposure assessment methodologies for residues of veterinary drugs: Final report including report of stakeholder meeting. Rome, Italy 2011.

Goetting V, Lee KA, Tell LA. Pharmacokinetics of veterinary drugs in laying hens and residues in eggs: a review of the literature. J Vet Pharmacol Ther. 2011;34:521-56. doi:10.1111/j.1365-2885.2011.01287.x.

JECFA. Evaluation of certain veterinary drug residues in food. Pilot of new approaches to estimate dietary exposure to veterinary drug residues. Seventy-eighth meeting of the Joint FAO/WHO Expert Committee on Food Additives (JECFA). WHO technical report series. WHO TRS 988. Geneva 2014.

Kabir J, Umoh V, Audu-okoh E, et al. Veterinary drug use in poultry farms and determination of antimicrobial drug residues in commercial eggs and slaughtered chicken in Kaduna State, Nigeria. Food Control. 2004;15:99-105. doi:10.1016/S0956-7135(03)00020-3.

Kao Y-M, Chang M, Cheng C, Chou S. Multiresidue determination of veterinary drugs in chicken and swine muscles by high performance liquid chromatography. J Food Drug Anal. 2001;9:84-95.

Kehinde OG, Junaidu K, Mohammed M, et al. Detection of antimicrobial drug residues in commercial eggs using Premi ${ }^{\oplus}$ Test. Int J Poult Sci. 2012;11:50-4.

Leibler JJH, Otte JM, Silbergeld KA, Ellen K. Risks and challenges risks associated with poultry production systems, Poult 21st Century. 2004. p. 1-12.
Li J, Huang L, Pan Y, et al. Tissue depletion of quinocetone and its five major metabolites in pigs, broilers, and carp fed quinocetone premix. J Agric Food Chem. 2014;62:10348-56. doi:10.1021/jf5042867.

Lykkeberg AK, Cornett C, Halling-Sørensen B, Hansen SH. Isolation and structural elucidation of tiamulin metabolites formed in liver microsomes of pigs. J Pharm Biomed Anal. 2006;42:223-31. doi:10.1016/j.jpba.2006.03.023.

McKellar QA, Jackson F, Coop RL, Baggot JD. Plasma profiles of albendazole metabolites after administration of netobimin and albendazole in sheep: Effects of parasitism and age. Br Vet J. 1993;149:101-13. doi:10.1016/S00071935(05)80213-1.

Mehdizadeh S, Kazerani HR, Jamshidi A. Screening of chloramphenicol residues in broiler chickens slaughtered in an industrial poultry abattoir in Mashhad, Iran. Iran J Vet Sci Technol. 2010;2:25-32.

Omeiza GK, Kabir J, Mamman M, Ibrahim H. Response of Nigerian farmers to a questionnaire on chloramphenicol application in commercial layers. Vet Ital. 2012:48:87-93.

Pavlov A, Lashev L, Vachin I, Rusev V. Residues of antimicrobial drugs in chicken meat and offals. Trakia J Sci. 2008;6:23-5.

Reig M, Toldra F. Veterinary drug residues in meat: Concerns and rapid methods for detection. Meat Sci. 2008;78:60-7. doi:10.1016/j.meatsci.2007.07.029.

Shankar S, Bp B, Prabhu M, et al. Rapid methods for detection of veterinary drug residues in meat. Vet World. 2010;3:241. doi:10.5455/vetworld.2010.241-246.

Solecki R, Davies L, Dellarco V, et al. Guidance on setting of acute reference dose (ARfD) for pesticides. Food Chem Toxicol. 2005;43:1569-93. doi:10.1016/j.fct.2005.04.005

Stolker AAM, Zuidema T, Nielen MWF. Residue analysis of veterinary drugs and growth-promoting agents. Trends Anal Chem. 2007;26:967-79. doi:10.1016/j.trac.2007.09.008.

Verbeke WAJ, Viaene J. Ethical challenges for livestock production: Meeting consumer concerns about meat safety and animal welfare. J Agric Environ Ethics. 2000;12:141-51. doi:10.1023/A:1009538613588.

\section{Submit your manuscript to a SpringerOpen ${ }^{\circ}$ journal and benefit from:}

- Convenient online submission

- Rigorous peer review

- Immediate publication on acceptance

- Open access: articles freely available online

- High visibility within the field

- Retaining the copyright to your article

Submit your next manuscript at $>$ springeropen.com 